ISSN: 2637-6679

\title{
We Take Care: A Punk Point of View to the Brand New Psychiatry
}

\author{
Collettivo Bisacco* \\ Working group of mental health Services, Italy
}

Received: 镐April 06, 2018; Published: 眥 April 11, 2018

*Corresponding author: Collettivo Bisacco, C/o centro Diurno Bisacco, Via Bidone 26 a, 10125 Torino Turin, Italy

\begin{abstract}
The Collettivo BISACCO is a mixed group of users, stakeholders and workers that cooperate in the Mental Health Service of Turin, Italy. The project started 5 years ago with a social art performance in Sebrenica- Bosnia. After we had collaboration with many institutions and international cultural events. Now with partnership of Associazione Insieme (a family association) and Gruppo Famiglia (the network of all family oriented practices) we started a new project. We promote a users oriented analysis of scientific report on the main topics of psychiatric studies. Now we are building up a group who shares scientific information's to promote a debate in the clinical world. This is a starting paper based on some of the discussion we had. We use a collective name because we refuse using patient's activities and direct expressed opinion to enhance personal careers. The name BISACCO is referred to a Turin psychiatrist who had an important role in the closure of psychiatric hospital in Turin and now is the name of the service (a little bit rehab, a little bit clubhouses and something more) where we meet.
\end{abstract}

\section{Opinion}

In 2010 Whitaker's book Anatomy of an epidemic was published. It contains a very interesting and successfully story on how the most important pharmaceutical industries controlled data and research to hide the dangerous consequence of psychotropic drugs. We said, story as fictional tale because, far from to be objective, the author draws a paradoxical portrait of psychiatrists and patients just to destroy them. When we read for the first time the book we were astonished and deeply moved, now 7 years are passed away and things are no more the same. We take up the book again but it seems so old fashioned like it was written decades ago. It could be a strange statement, because in the last years the debate started and it is going on today. Moncrieff [1] Whitaker [2], Goetze (2017), with the radical assumption that we must stop using all the psychotropics drugs, except for minima doses of anti psychotic for their harms and little benefits.

We try to look at the issue from a very different point of view; in fact we assume that drugs are not the matter. They can be useful, partially useful or harmful, it depends from individual responsiveness and pathology, The heart of the matter we have to face is which are the responsibilities of a capitalistic system promoting the systematic drop out from economic and social system of people with any kind of mental disabilities. In some way Whitaker and Goetze made an involuntary wonderful spot to pharmaceutical industry leading people (pros or cons) to speak about the drugs, focusing on them like the only tool that can drive people to be healthy or sick. The book was published in the 2010, but it takes a lot of time to be finished, so it speaks from a social and economics point of view of a dead world. The Lehman Brothers crisis has radically changed our perspective.

We don't want to discuss the W's thesis. A lot of people more qualified have just done it. We want radically change his observation point. He starts speaking from a wonderful, peaceful and relaxing library where every scientific journal and books are collected and you can look at knowledge builted up in decades. Well, get out of there and go down in the streets. In 2016 Rosenbaum states that of 9.8 million U.S. adults with serious mental illness, an estimated $40 \%$ receive no treatment in any given year. Those who get care often face protracted delays: the average lag between onset and treatment of major depressive disorder, for instance, is 8 years. Beyond homelessness, the clear consequences of under treatment 
include fractured relationships, joblessness, victimization, substance abuse, incarceration, and early death. The causes of under treatment, however, are less obvious.

a. underfunding of mental health care in all domains, low community resources, adequate reimbursement, better training for professional;

b. side effects of medication that are unacceptable, about $74 \%$ of patients discontinue treatment by 18 months;

c. Many people don't seek a treatment simply because they don't think to have any problem at all.

We tend to focus on structural problems, which are objective and often quantifiable. But the structural impediments to care can't be addressed without reconciling the conflicting ideals underlying them. There is an underlining belief that all these people can be healthier without intervention. All the brand new psychiatry followers had a main refrain. Before introduction of clorpromazina outcome of schizophrenia was better, patients recovered after 18 months with very high percentage and returned to their life with high \% of employment and a good social life [2].

\section{What a wonderful world was America}

A person meets you and says: „Hey man are you schizophrenic? Great! Don't mind only few months and you will be out of it. We will wait you, we keep your job apart and we will make a party to met some girls“. In spite of this de-institutionalization, the closing of state mental hospitals that was initiated in the mid-1950s is often blamed for the fragmentation of mental health care. Sick people were released, but promised resources for community-based care never materialized. One consequence was "trans-institutionalization", prisons take the place of hospital. (Rosenbaum)Now recovery is the new line of horizon. What is recovery? U.S. Substance Abuse and Mental. Health Services Administration (SAMHSA) has adopted a recovery mission, defining recovery as "a process of change through which individuals improve their health and wellness, live a self-directed life".

We agree, but this is a politic and economic struggle for each persons and it cannot be limited to psychiatric patient. Talking back to fab 50es and recovery. Psychiatric hospital in Italy and we guess about all the rural countries in the world selected mainly people who wasn't able to work in a sustainable way. For the main part of them going back to the family and recovery was quite a nightmare. An often person with mental disabilities was treated like beast of burden in fields or little factories. Are things quite different now? As in many fields of economic and social life the challenge is between developing, newly developed and developed countries. In a wonderful paper Vikram Patel, Shuiyuan Xiao, Hanhui Chen, Fahmy Hanna, A T Jotheeswaran, Dan Luo, Rachana Parikh, Eesha Sharma, Shamaila Usmani, Yu Yu, Benjamin G Druss, Shekhar Saxena [3] makes a clear and objective analysis of mental health state in both India and China.
They observe that poor quality of care and violations of human rights, including involuntary admittance to an institution, abandonment by family members, restrictions and isolation, and inadequate living conditions, are longstanding concerns in mental hospitals in both China and India. Brutal practices such as chaining and incarceration, social exclusion, and denial of employment and education are documented in both countries. We report below an extract of their description of the political programs in both countries.

\section{Disorders}

Primary government program in China is the National Continuing Management and Intervention Program for Psychoses, known as the 686 Program, launched in 2004, which reported training of over 10000 psychiatrists (nearly $50 \%$ of all psychiatrists in China) and seven times expansion in the national community mental health service network between 2006 and 2011. The National Mental Healthcare System Guidelines (2008-2015) aimed to set up mental health clinics in $60 \%$ of primary and middle schools in urban areas by 2015 , and provision of mental health-care at the community level in $85 \%$ of counties and cities. These objectives were not met, and several of these goals are now reiterated in the National Mental Health Plan for 2015-2020, which also envisages providing rehabilitative services in $70 \%$ of the counties by 2020 .

As an active step to increase service coverage, China's National Mental Health Law, effective from May, 2013, instructs all general hospitals to provide mental health services and support community-based rehabilitation services. In India, the primary governmental response has been through the National Mental Health Program (NMHP), launched in 1982. After initially supporting a few demonstration projects and the state-run mental hospitals, NMHP underwent a paradigm shift, when the District Mental Health Programmer (DMHP) was launched in 1996 with the goal of providing community oriented services. As of April, 2015, the DMHP was expected to cover 241 districts (36\% of all districts in the country). When effectively implemented, the program has successfully reduced use of inpatient mental health services. However, the effectiveness of the program varies across the states because of restricted funding, shortages of human resources, and low motivation. Similarly, India's pending draft Mental Health Care Bill 2013 seeks to mandate registration of all hospitals admitting people with mental disorders as mental health establishments, improve protection for human rights, and provide free legal aid and a right to complain against deficiencies in care. Welfare measures such as pensions, legal aid, and travel concessions are available for people with schizophrenia and intellectual disabilities through the Persons with Disabilities Act 1995 [4,5].

In the same paper authors state that in China the difference in employment for psychiatric patient's moves from $95 \%$ in rural areas to 23 in urban ones. Are drugs responsible of this? We must repeat that the outcome of psychiatric patients is mainly a socioeconomic 
variable, more than a clinical one. Kids aren't all right. All the cycle of economic expansion and all the developing countries had unemployment rates close to zero. In this way the work of people with mental disabilities can be interesting to the system even if not very efficient. On other side the political/economical system has the concern to leave the less efficient part of the workforce during the economical depression out of the production cycle. Disability benefits have the task of guaranteeing social peace at the price of social exclusion of people with psychic weakness. Italy is lucky. People with psychiatric disability receive only 289 Euros (about 350 USD) not enough to sustain an autonomous live, without intervention of family support for home and income.

This happens not only to psychiatric patient's families. In Italy the unemployment rate for people under 25 year old has a range from $25 \%$ in the North to more than $50 \%$ in the South. Finally we have filled the gap between normal young people and the others. No one, except for the most able of them, has a real chance to build „a self-directed life". What does it mean promote the personal abilities if we cannot find a social opportunity to use them? We don't believe anymore to the psychological weltanschauung of inner change. What should we tell to a young recovered patient? OK, now you are well, so look at the mirror all day and think how you are lucky. Rehab services, community-based treatment can be useful in some point of the way, but after some times the reality must take their place. We have to observe that from now we need a radical change in welfare politics oriented to mental health not to reimburse the deficit but to promote individual skills and abilities using them in a partially productive way inside the economic system. Rhythms job organization is still tailored on oldest production system. Is it really the only way we have to think for social inclusion of mental health patients?

\section{We guess we have to proceed in three steps}

a. on the clinical side develop psychotherapy and rehab approach to have resource oriented patients (and network) strategies

b. on the social side use artistic and social media to promote new ways to see at mental health and identify social network resource

c. On the political side promote laws to give economical support to patient oriented job opportunities.

In the next paper we will explore with more accuracy these statements, also referring to what's going on in Italy, with a special regard to our city. Use everything you need to fight the power and have a better life.

\section{References}

1. Moncrieff J (2008) The myth of the chemical cure: a critique of psychiatric drug treatment. Basingstoke: Palgrave Macmillan.

2. Robert Whitaker (2010) Anatomy of an Epidemic, magic bullets, psychiatric drugs and the astonishing rise of mental illness in America. Crown Publishing Groups.

3. Vikram Patel, Shuiyuan Xiao, Hanhui Chen, Fahmy Hanna, AT Jotheeswaran et al. (2016) The magnitude of and health system responses to the mental health treatment gap in adults in India and China, Lancet pp. 3074-3084.

4. Peter C Goetzche, Allan H Young (2015) does long term use of psychiatric drugs cause more harm than good? pp. 350.

5. Lisa Rosenbaum (2016) Liberty versus Need-Our Struggle to Care for People with Serious Mental Illness, New Englandn engl j med pp. 375.
To Submit Your Article Click Here : Submit Article

DOI: 10.32474/RRHOAJ.2018.01.000117

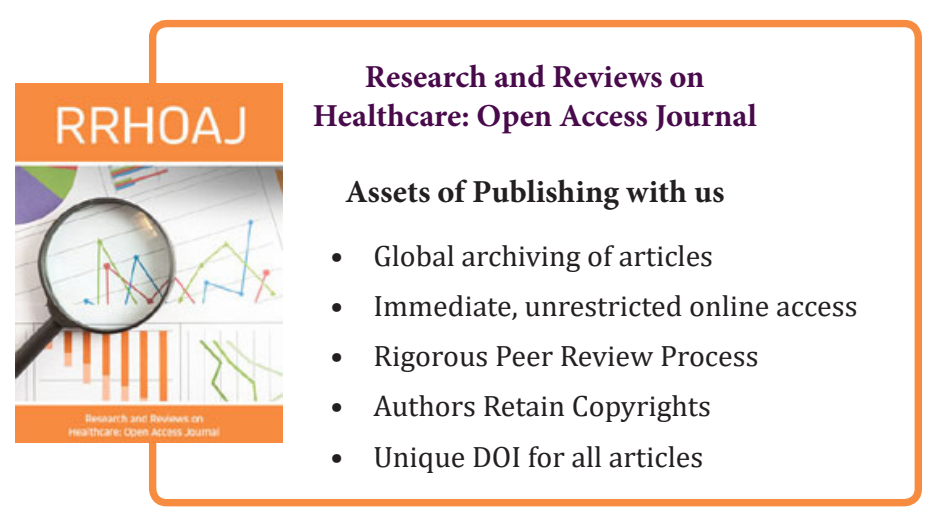

